\title{
Decrease in cell size and cell wall components under ectopic expression of the CaRLK1 gene
}

Dong Ju Lee ( $\square$ leedongju@gmail.com )

https://orcid.org/0000-0002-0348-5694

\section{II-Chul Kim}

Chonnam National University

\section{Seungwoo Jeong}

Chonnam National University

\section{Seung Gon Wi}

Chonnam National University

\section{Suk Weon Kim}

Korea Research Institute of Bioscience and Biotechnology

\section{Woo Seok Ahn}

Korea Research Institute of Bioscience and Biotechnology

\section{Research article}

Keywords: CaRLK1, cell wall, CESA, expansin, GA2ox, polygalacturonase, small size, suppression

Posted Date: July 7th, 2020

DOI: https://doi.org/10.21203/rs.3.rs-36059/v1

License: (c) (i) This work is licensed under a Creative Commons Attribution 4.0 International License.

Read Full License 


\section{Decrease in cell size and cell wall components under ectopic expression of the CaRLK1 gene}

running head: Smaller cell size

Dong Ju Lee ${ }^{1,2^{*}}$, Il-Chul Kim² ${ }^{2}$, Seungwoo Jeong ${ }^{3}$, Seung Gon $\mathrm{Wi}^{4}$, Suk Weon $\mathrm{Kim}^{5}$, Woo Seok $\mathrm{Ahn}^{5}$

*Corresponding Author: Dr. Dong Ju Lee

Tel: 82-62-530-3390, HP: 82-10-8214-0117, Fax: 82-62-530-3409

E-mail: leedongju@gmail.com

ORCID-ID: https://orcid.org/0000-0002-0348-5694

Basic Science Institute ${ }^{1}$, School of Biological Sciences ${ }^{2}$, School of Biological Science and Technology ${ }^{3}$, Asian Pear Research Institute ${ }^{4}$, Chonnam National University, 77 Youngbongro, Buk-gu, Gwangju 61186 Republic of Korea

Biological Resource Center ${ }^{5}$, Korea Research Institute of Bioscience and Biotechnology, 181 Ipsin-gil, Jeongeup-si, Jeollabuk-do, 56212, Republic of Korea.

1. Dong Ju Lee; leedongju@gmail.com

2. Il-Chul Kim; ickim@chonnam.ac.kr

3. Seungwoo Jeong; nlkjjm@naver.com

4. Seung Gon Wi; sgwi_2000@yahoo.co.kr

5. Suk Weon Kim; kimsw@kribb.re.kr

6. Woo Seok Ahn; dntjr0412@kribb.re.kr 


\begin{abstract}
Background

The Capsicum annuum receptor-like kinase 1 (CaRLK1) gene encodes a transmembrane protein with a cytoplasmic kinase domain and an extracellular domain. It functions as a negative regulator of plant cell death. Ectopic expression of CaRLK1 showed the hypoxiaresistance and enhanced cell division and proliferation. In this study, it was investigated which genes were controlled by ectopic expression of CaRLK1 because it decreased its average cell size of transgenic RLK1ox cells compared with that of wild-type cells (BY-2).

Results
\end{abstract}

The average diameter (AD) of the protoplast of RLK1ox cells was about $10 \mu \mathrm{m}$ shorter than the AD of BY-2 cells. The diameter distribution of the circular protoplasts is mainly from 20 to $40 \mu \mathrm{m}(71.7 \%)$ in RLK1ox cells, whereas from 30 to $50 \mu \mathrm{m}(73.0 \%)$ in BY-2 cells. Furthermore, cell volume of RLK1ox cells is also 2.5-times smaller than that of BY-2 cells. Smaller cell size of the RLK1ox cells may be related with the inhibited cell expansion because expressions of 12 expansin $A$ genes, 6 expansin-like $B$ genes, $2 A C C$ synthase genes, and 5 ACC oxidase genes were suppressed, but expressions of 7 gibberellin 2-oxidase genes were induced.

The cell walls between two RLK1 ox cells are approximately $138.83 \pm 4.12 \mathrm{~nm}$ thick on average, while those between two BY-2 cells are approximately $156.58 \pm 4.54 \mathrm{~nm}$ thick. Furthermore, the total content of neutral sugars in the cell wall of RLK1ox cells is less than that of BY-2 cells (about 25\%). The RLK1ox cells contained 30\% less glucose content than did the BY-2 cells. Thinner cell wall of the RLK1ox cells is related with the decreased cellulose biosynthesis and hemicellulose biosynthesis. Expressions of 7 CESA genes, 5 sucrose synthase 1 genes, 3 mannose-1-phosphate guanyltransferase genes, and 6 glucomannan-4-beta- 
mannosyltransferase genes were suppressed. The suppressed expressions of 14 polygalacturonase genes may also contribute to make the cell wall of RLK1ox cell thinner than that of BY-2 cell.

\section{Conclusion}

Of special emphasis is its impact of CaRLK1 gene on cell size control and cell wall thickness. Smaller cell size of the RLK1ox cells correlates with the inhibited cell expansion.

Keywords: CaRLK1, cell wall, CESA, expansin, GA2ox, polygalacturonase, small size, suppression

\section{Background}

It is known that cell size is related to the physiological state of the plant cell $[1,2]$. Therefore, the cell size distribution directly reflects the average physiological properties of the suspension cell culture. Cells need to be small because they need a high 'surface to volume' ratio, which is good for exchanging materials (ions, organic molecules, and waste) between the inside and outside of cells.

The plant cell wall, as a dynamic structure, plays important roles in controlling the differentiation of plant cells during embryogenesis and growth, including cell enlargement, cell proliferation, and fruit softening. The primary cell wall of land plants is composed of the polysaccharides cellulose, hemicelluloses and pectin [3-5]. Cellulose is an important structural component of the primary cell wall of green plants and plays a central role in determining the mechanical properties of plant cell walls. Cellulose is an organic compound consisting of a linear chain of glucose units. Hemicellulose is one of a number of heteropolymers (matrix polysaccharides), including xylan, glucuronoxylan, arabinoxylan, glucomannan, and xyloglucan. Thus, hemicelluloses include the five-carbon sugars xylose and arabinose, the six- 
carbon sugars glucose, mannose and galactose, and the six-carbon deoxy sugar rhamnose. Glucomannan is a water-soluble polysaccharide that is considered a dietary fiber. This polysaccharide acts as a hemicellulose component in the cell walls of some plant species. Pectin is a highly hydrated network of structural acidic heteropolysaccharides rich in galacturonic acid. Pectin is mainly found in the middle lamellae in the primary cell walls of virtually all terrestrial plant cells. In primary cell walls, the matrix in which the cellulose network is embedded is composed of pectin.

Cellulose is synthesized at the plasma membrane by a large multiprotein complex, known as the cellulose synthase complex (CSC) $[6,7]$. CSCs contain multiple nonredundant cellulose synthase A(CESA) proteins that serve as CSC catalytic subunits. The CESA1, CESA3, CESA6, and CESA9 genes are involved in primary cell wall cellulose biosynthesis [7]. Cellulose synthesis in secondary walls involves three functionally nonredundant secondary wall CESAs belonging to the glycosyltransferase family 2 (CESA4, CESA7, and CESA8).

During organ development, plant cells can be enlarged considerably by the expansion process, where water accumulates internally through osmosis and plant cells have a rigid cell wall surrounding the plasma membrane [5]. Such hormones as auxins, gibberellins, ethylene, and cytokinins direct the coordinated growth and proliferation of plant cells. Expansins[8] and polygalacturonase (PG) [9] are known to be responsible for loosening the structure of the wall. Expansins (EXP) were discovered to expand growing plant cell walls faster at low (acidic) pH than at neutral $\mathrm{pH}$ and to influence the structure of cellulose/hemicellulose frameworks. The mRNA levels of expansin genes and expansin protein levels are strongly correlated with the growth and development of root and shoot organs [10, 11]. The expression of CaEXPA14 and CaEXPA19 positively correlated with the rate of cell expansion in bell pepper [12]. Expansins have been shown to bind strongly to cellulose and to allow loosening of the wall by disrupting the hydrogen bonds. Expression of both EXPAs and EXPBs was associated with internode 
elongation in deep-water rice [13]. Expansins are wall-loosening proteins implicated in plant responses to most of the major plant hormones, such as auxin [8], gibberellin (GA) [14], cytokinin [15], and ethylene [16], in several organs and species. AtEXP8 and AtEXP18 in Arabidopsis [17] and $O s E X P 1$ and $O s E X P 2$ in rice [18] are responsive to ethylene. Four expansins ( $E X P A 4, E X P A 5, E X P A 7$, and $E X P B 4)$ are upregulated by GA treatment during GA stimulation of leaf elongation in Festuca arundinacea [19]. Submergence-induced petiole elongation enables $R$. palustris to emerge from flooded environments. Ethylene promotes the transcription of an expansin gene (RpEXPA1) in R. palustris [20, 21]. The Brassica rapa expansin-like $\mathrm{B} 1$ gene $(B r E X L B 1)$ regulates growth and development in transgenic Arabidopsis and elicits responses to abiotic stresses. Overexpressors of sense BrEXLB1 enhance plant height [33].

Polygalacturonase (EC 3.2.1.15) is an enzyme that hydrolyzes the $\alpha-1,4$ glycosidic bonds between galacturonic acid residues. This enzyme is a pectinase that degrades pectin to soften and sweeten fruit. Ethylene increases PG, which degrades pectin to loosen the cell wall. ACC (1-aminocyclopropane-1-carboxylate) synthase (ACS) catalyzes the rate-limiting step of ethylene biosynthesis [22]. ACS6 (At4g11280) was unregulated by ABA, BL, and IAA. ACS10 (At1g62960) was downregulated by ABA, IAA, MJ, and GA. The activities of GA 20-oxidases (GA20ox), GA 3-oxidases (GA3ox), and GA 2-oxidases (GA2ox) are of particular importance in determining gibberellin (GA) concentration in many plant species [23, 24]. Cellular accumulations of gibberellins regulate cell growth in developing embryos, elongating stems and roots, and developing floral organs. GA2ox enzymes catalyze the main inactivation step through 2-oxidation of both the bioactive forms and their precursors. Thus it can inhibit cell expansion by reducing the concentration of the bioactive GAs.

Tobacco BY-2 cell (Nicotiana tabacum) has been employed as a model cell in various aspects in plant physiology [25]. BY-2 cell is very useful to investigate the dynamics of a single 
type of plant primary cell wall.

The functions of CaRLK1 gene (Capsicum annum receptor-like kinase1) isolated from hot pepper [26] are associated with suppressing plant cell death, hypoxia resistance, and promoting cell division $[27,28]$. The amino acid sequences of $C a R L K 1$ gene are very similar to leaf rust resistance kinase Lr10 genes of the Solanaceae family including pepper, tomato and tobacco. In the previous result, overexpression of $C a R L K 1$ gene promotes cell division with decreased cell size [28]. Thus, we are very interested in elucidating how ectopic expression of the CaRLK1 gene regulates cell size and cell wall thickness. In this study, the overall goal was achieved to elucidate the biological and genetic mechanisms; which genes are highly regulated under ectopic expression of the CaRLK1 gene.

\section{Results}

\section{Cell size distribution}

In general, eukaryotic cells have diameters ranging from 10 to $100 \mu \mathrm{m}$. As a cell decreases in size, its surface area-to-volume ratio increases. Ectopic expression of the CaRLK1 gene in $N$. tabacum BY-2 cells decreased cell size: The average diameter of the RLK1ox protoplasts was smaller than that of the protoplasts (named as BYK) to that the control vector was introduced [28]. The AD and diameter distribution (DD) of the protoplast were chosen as the evaluation criteria for the cell size test. A detailed analysis of representative protoplasts showed that the AD of RLK1ox cells was $30.53 \pm 0.37 \mu \mathrm{m}$ on average, whereas the AD of BY2 control cells was $41.38 \pm 0.40 \mu \mathrm{m}(\mathrm{n} \geq 500)$ (Fig. 1A). The BY-2 cells grew to an average volume of $37,081 \mu \mathrm{m}^{3}$, whereas the RLK1ox cells grew to an average volume of $14616 \mu \mathrm{m}^{3}$, indicating that the size of RLK1ox cells is considerably smaller than that of BY-2 cells. Thus, the cell volume of RLK1 ox cells also decreased more than 2.5-fold. In addition, the BY-2 cells 
grew to an average surface area of $5377 \mu \mathrm{m}^{2}$. However, the RLK1ox cells grew only to an average surface area of $2890 \mu \mathrm{m}^{2}$ (data not shown).

A variation in DD was observed when 7-day-old cells were compared (Fig. 1B). The DDs of BY-2 cells and RLK1ox cells were not similar to each other. In the range of 10-50 $\mu \mathrm{m}$, the DD in RLK1ox cells is over $85 \%$, whereas the DD in BY-2 cells is less than $43 \%$. This result indicates that the small cell size of RLK1ox cells is considerably more than that of BY2 cells.

Cells need to be small because they need a high 'surface to volume' ratio, which enables them to rely on oxygen and material diffusing into the cell and waste diffusing out to survive and grow. Thus, smaller RLK1 ox cells have a higher surface area to volume ratio (1.21fold) than larger BY-2 cells, indicating that RLK1ox cells are better for exchanging materials (ions, organic molecules, oxygen, and waste) between the inside and outside of cells than BY2 cells.

\section{Thin cell walls}

Ectopic expression of the CaRLK1 gene in a Nicotiana tabacum BY-2 background promotes proliferation at an approximately 3 -fold higher rate than wild-type BY-2, either in suspension culture or on solid medium [28]. Thus, we hypothesized that the cell walls of fastdividing RLK1ox cells are thinner than those of relatively slow-dividing BY-2 cells.

The thickness of the cell walls was measured by transmission electron microscopy (TEM). The thickness of a double cell wall layer between two RLK1ox cells appeared narrower than that between two BY-2 control cells (Fig. 2A and 2B). The TEM images in Figure 2B reveal representative images of a double cell wall layer of either BY-2 cells or RLK1ox cells. The thickness of a double cell wall layer of the transformed cells (RLK1ox cell) is, on average, $138.83 \pm 4.12 \mathrm{~nm}$, whereas that of BY-2 control cells was $156.58 \pm 4.54 \mathrm{~nm}$ (Fig. 2A). In addition, 
the cell walls of a single layer in the RLK1ox cells were also considerably thinner than those in the BY-2 control cells (Fig. 2C). The thickness of a single cell wall layer of the RLK1ox cells is, on average, $102.79 \pm 2.68 \mathrm{~nm}$, whereas that of BY-2 control cells was $171.55 \pm 5.58 \mathrm{~nm}$ (Fig. 2C). Figure 2D presents a representative TEM image showing the cell wall thickness of a single layer of BY-2 cells and RLK1 ox cells. These observations indicate that the cell wall of RLK1ox cells is clearly thinner than that of BY-2 cells. These results suggest that cellulose biosynthesis in the RLK1ox cell is relatively inhibited than in the BY-2 cell. Generally, the advantage of thinner cell wall is that substances, such as oxygen, organic molecules, and ions, can diffuse easily into the cell whereas wastes can diffuse out easily out of cell. This result suggests that RLK1ox cell is better to survive and to proliferate than BY-2 cell.

\section{Neutral sugar contents of the cell wall}

Differences in wall thickness may be due to differences in the amount of cell wall components [29]. The amount of 6 neutral sugars from cell walls was quantified (glucose, galactose, mannose, xylose, arabinose, and rhamnose). The total neutral sugar content of purely extracted cell walls was lower in the RLK1ox cells than in the BY-2 control cells $(n=3)$. The sum of neutral sugars in the wild-type cells constituted approximately $22.3 \%$ of the total weight of the extracted cell wall, whereas the sum of average neutral sugars in the RLK1ox cells made up only $17.3 \%$ of the total weight of the extracted cell wall (Fig. 3).

The contents of glucose, mannose, arabinose, and xylose were consistently lower in the RLK1ox cells than in the wild-type cells (Fig. 3). This result suggests that the biosynthesis of cellulose and hemicellulose polysaccharides (xylans, xyloglucans, mannans and glucomannans) are defective in fast-dividing RLK1ox cells.

This observation suggests that both the biosynthesis and incorporation of cell wall components is relatively slower in RLK1ox cells than in BY-2 cells, indicating a dynamic 
process of cell wall biosynthesis that is tightly downregulated during cell growth in RLK1ox cells. Plant cells surround themselves with a cell wall that greatly limits exchange materials with the extracellular world. Thus, the thinner cell walls

\section{Expression of CESA genes}

We used a Nimblegen Nicotiana tabacum 135K microarray (GreenGene Biotech, Seoul, ROK) to evaluate the upregulation and downregulation of $N$. tabacum genes. CESA genes are believed to encode the catalytic subunit of plant cellulose synthase. It is important to investigate whether the expression of tobacco CESA genes is changed by introducing the CaRLK1 gene into BY-2 cells because the cell wall is thinner in RLK1ox cells and the neutral sugar content of the cell walls is decreased in RLK1ox cells compared to BY-2 cells.

A total of $14 C E S A$ genes were detected in the microarray analysis. The $p$-value of eight genes among them was lower than 0.05 . The expression levels of seven genes were decreased in RLK1ox cells, except for the CESA8 gene (Fig. 4). Although the expression of CESA8 (cellulose synthase A catalytic subunit 8) appears to be strongly induced in RLK1ox cells, its expression level is notably low. CESA8 is known to be involved in the biosynthesis of the plant secondary cell wall (SCW). The expression of six CESA genes (three CESA1, two CESA3, and one CESA9) is relatively high in BY-2 cells. However, the expression of these genes is suppressed in RLK1ox cells (Fig. 4). These six genes are known to be involved in the biosynthesis of the plant primary cell wall (PCW). The suppressed expression of the CESA1, CESA3, and CESA9 genes may affect the biosynthesis of the primary cell wall in RLK1ox cells. This observation suggests that decreased expression of six CESA genes may be associated with a decrease in cell wall thickness and neutral sugar content in RLK1ox cells.

\section{Expression of glucomannan 4- $\beta$-mannosyltransferase genes}


Glucomannan 4- $\beta$-mannosyltransferase (or glucomannan synthase, CSLA9, GMMT) is an enzyme that catalyzes the biosynthesis of glucomannan, a hemicellulose component, using GDP-mannose and glucomannan polymers. A total of six GMMT genes were detected in the microarray analysis. The $p$-value of these genes was lower than 0.008 . The expression levels of 6 genes were determined to be decreased in RLK1ox cells (Fig. 5A). In particular, three genes (Ntabacum_ESTC011116; GMMT2-1, Ntabacum_ESTC000635; GMMT2-2, and Ntabacum_ESTC000636; GMMT2-3) that are relatively highly expressed in BY-2 cells are suppressed in RLK1ox cells. In addition, mannose-1-phosphate guanylyltransferase catalyzes the biosynthesis of GDP-mannose, a substrate for glucomannan 4- $\beta$-mannosyltransferase. The expression of three genes among the 4 detected mannose-1-phosphate guanylyltransferase genes slightly decreased in RLK1ox cells (Fig. 5B). These results suggest that the suppression of two kinds of genes may decrease the mannose and glucose content of hemicellulose in the primary cell wall of RLK1ox cells.

\section{Expression of polygalacturonase (PG) genes}

The developmental changes during tomato fruit ripening include increased solubilization and depolymerization of pectins due to the action of polygalacturonase (PG) [9, 30]. Pectin are major constituents of primary cell walls in eudicots. PGs, as pectinases, are key homogalacturonan-hydrolyzing enzymes that function in a wide range of developmental processes. $P G$ genes were detected in microarray analysis. The $p$-value of seventeen $P G$ genes among them is lower than 0.05 . The expression levels of fourteen $P G$ genes decrease in RLK1ox cells. The expression levels of $10 P G$ genes among 14 genes are decreased more than

2 times in RLK1ox cells than in BY-2 cells (Fig. 6). The constitutive suppression of $P G$ in RLK1ox cells may provide a phenocopy of cell wall-deficient transgenic cells for defining the functions of the RLK1ox cells, resulting in thin cell walls. 


\section{Expression of GA2ox genes}

Gibberellins (GAs) are plant hormones that regulate various developmental processes, including stem elongation, germination, dormancy, flowering, and flower development. In this study, we showed that 7 different GA2ox genes are induced in RLK1ox cells compared with control BY-2 cells (Fig. 7A). A total of 9 GA2ox genes were detected in the microarray analysis. The $p$-value of 7 genes among them is lower than 0.012 . The expression levels of these 3 GA2ox genes (GA2ox2, GA2ox3-1, and GA2ox4) are relatively strongly induced in RLK1ox cells, whereas the expression levels of the other 4 genes are slightly induced. The expression of two genes (GA2ox2 and GA2ox3-1) is highly induced by qRT-PCR (Fig. 7B and 7C). The highly induced GA2ox genes may decrease the active gibberellin concentration in RLK1ox cells. These data suggest that a low concentration of active GAs is correlated with smaller cells and negative cell expansion in RLK1ox cells. However, the expression of two GA20ox genes (GA20ox1; Ntabacum_ESTC018089 and GA20ox2; Ntabacum_ESTC015362) and one GA3ox (Ntabacum_ESTC021120) gene is not induced in RLK1ox cells (data not shown), suggesting that GA2ox genes is related with small cell size. The $p$-value of these 3 genes is higher than 0.18 .

\section{Expression of expansin genes}

Expansins are known to be cell wall proteins that mediate acid-induced growth by catalyzing the loosening of plant cell walls without lysis of wall polymers [3]. Cell elongation is controlled by cell extensibility, which is regulated by cell wall-loosening proteins and enzymes, including expansin and xyloglucan endotransglycosylase (XET) [31]. It was reported that EXPA4 was highly expressed in germinating seeds and that EXPA3 was highly expressed in young roots and germinating seeds in tobacco [32]. 
A total of 28 expansin $A(E X P A)$ were detected in the microarray analysis. The $p$-value of sixteen genes among them is lower than 0.015 . The expression of these genes is inhibited in the RLK1ox cells, except for four genes (EXPA6-2, EXPA10-1, EXPA11-2, and EXPA12), which are slightly induced (Fig. 8A). Genome-wide gene expression analysis showed that the expression of six EXPA genes is strongly suppressed more than twofold in RLK1ox cells. In particular, the expression of EXPA3-1 (Ntabacum_ESTC008617) and EXPA4 (Ntabacum_ESTC004061) is significantly suppressed in RLK1ox cells. qRT-PCR analysis confirmed that the expression of the EXPA4 gene is suppressed approximately 2-fold and that the expression of the EXPA11-1 gene is strongly suppressed approximately 5-fold in RLK1ox cells compared to BY-2 cells (Fig. 8B, 8C).

Overexpressors of sense $B r E X L B 1$ enhance plant height compared with wild-type plants [33]. The EXLB1 gene was reported to be highly expressed in young roots and mature roots [32]. A total of 7 expansin-like B1 (EXLB1) genes were detected in the microarray analysis. The $p$-value of six genes among them is lower than 0.029. Genome-wide gene expression analysis showed that the expression of all six EXLB1 genes is strongly suppressed more than twofold in RLK1ox cells (Fig. 8D). In particular, the expression of EXLB1-4 (Ntabacum_ESTC017701), which is highest among the six EXLB1 genes in BY-2 cells, is significantly suppressed in the RLK1ox cells ( $<3.65$-fold). qRT-PCR analysis confirmed that the expression of the EXLB1-4 gene is suppressed approximately 2-fold in RLK1ox cells compared to BY-2 cells (Fig. 8E). qRT-PCR analysis confirmed that the expression of the EXLB 1-4 gene is strongly suppressed by approximately 9-fold in RLK1ox cells compared to BY-2 cells.

However, a total of 6 expansin-like $A$ genes (EXLA) were detected in the microarray analysis. The $p$-value of three EXLA2 genes among them is lower than 0.001 (Table S2). However, the expression of these genes increases slightly in the RLK1ox cells (their fold 
change is less than 1.68), and their expression levels are relatively high in BY-2 and RLK1ox cells (Table S2). These results suggest that 3 EXLA2 genes may play important roles in cell division, rather than cell elongation, in RLK1ox cells.

\section{Expression of ethylene biosynthesis genes}

ACC synthase (ACS) is the key regulatory enzyme in the ethylene biosynthetic pathway, and ACC oxidase (ACO) converts 1-aminocyclopropane-1 carboxylic acid (ACC) to ethylene [22]. A total of 7 ACS genes were detected in the microarray analysis. The $p$-value of the three genes among them is lower than 0.005. The expression of two genes (Ntabacum_ESTC015881 and Ntabacum_ESTC002216) decreases in the RLK1ox cells (their fold change was more than 1.90) (Fig. 9A). In particular, the steeply decreased expression of the Ntabacum_ESTC002216 gene may contribute to the decrease in ethylene concentration in the RLK1ox cells because it is expressed at the highest level among the 3 genes in BY- 2 cells. qRT-PCR analysis confirmed that the expression of the ACS (Ntabacum_ESTC002216) gene is greatly suppressed approximately 12-fold in RLK1ox cells compared to BY-2 cells (Fig. 9B). However, the expression level of one gene (Ntabacum_ESTC004582) is notably low in both BY-2 cells and RLK1ox cells and is slightly induced in RLK1ox cells (its fold change is less than 1.60).

A total of $17 A C O$ genes were detected in the microarray analysis (Fig. 9C). The $p$-value of nine genes among them is lower than 0.033 . The expression levels of seven genes are notably low in both BY-2 cells and RLK1ox cells. However, the expression level of one $A C O$ gene (Ntabacum_ESTC020923) is highest in BY-2 cells but decreases by 2.6-fold in RLK1ox cells. qRT-PCR analysis confirmed that the expression of Ntabacum_ESTC020923 is strongly suppressed by more than 53-fold in RLK1ox cells compared to BY-2 cells (Fig. 9D). Sadenosyl-1-methionine (SAM) is a ubiquitous methyl donor and a precursor in the biosynthesis 
of ethylene in plants. SAM synthase is involved in the synthesis of SAM. The expression levels of $4 S A M$ synthase genes are not notably changed and show no significant regulation of ethylene biosynthesis (Fig. S4). Thus, ethylene biosynthesis in RLK1ox cells is decreased, primarily due to suppression of the expression of both $A C O$ genes and $A C S$ genes, rather than SAM synthase expression.

\section{Discussion}

Our results show that ectopic expression of the $C a R L K 1$ gene negatively regulates cell size and cell wall biosynthesis based on analyses of (1) smaller protoplast size; (2) narrower cell wall thickness, as measured by TEM analysis; (3) low contents of cell wall neutral sugars, (4) suppression of CESA genes, SUS1, PG, and expansin genes; (5) high induction of GA2ox and XET genes; and (6) suppression of the ethylene biosynthesis genes $A C O$ and $A C S$.

Cell wall thickness and the amount of cell wall components were investigated for a possible explanation for the smaller protoplast size of RLK1ox cells. Cellulose is synthesized at the plasma membrane by a large protein complex, known as the cellulose synthase complex (CSC). The primary wall CESA complex consists of three CESA subunits, namely, CESA1, CESA3, CESA6, and CESA9 [34]. In the RLK1ox cells, the expression of three kinds of primary cell wall CESA complex genes (two CESA1 genes, two CESA3 genes, and two CESA9 genes) was also downregulated (Fig. 4). Sucrose synthase 1 (SUS1) is not only the source of UDPglucose for cellulose synthesis but also part of a large soluble catalytic domain of the CESA complexes, which are involved in cellulose production by channeling UDP-Glc to the catalytic subunits of the CSC $[35,36]$. The expression of all 5 SUS1 genes was decreased in RLK1ox cells (Fig. S1). Low expression of SUS1 genes can decrease cellulose biosynthesis in the primary cell wall due to the reduction of UDP-Glc, a substrate for CSCs. These observations can explain how lower amounts of both primary cell walls and neutral sugar contents occurred 
in RLK1ox cells compared with BY-2 cells.

Expression of a WEE1 gene (Ntabacum_ESTC006562) increases more in RLK1ox cells than in control cells in 0- to 3-day-old culture (Fig. S2) and in the microarray analysis (Table S2). This result suggests that upregulation of WEE1 gene under the control of CaRLK1 gene makes RLK1ox cells smaller than BY-2 cells, as both constitutive and induced expression of Arath; WEE1 in BY-2 cultures results in a reduction in mitotic cell size [37]. In addition, in RLK1ox cells the suppressed expression of both ACS genes and ACO genes may contribute to decreased ethylene biosynthesis (Fig. 9) and may not have a positive effect on inducing cell expansion through stimulation of expression of Expansin11 gene, such as in petioles [38]. A negative regulator of the ethylene response pathway, serine/threonine-protein kinase Constitutive triple response1 (CTR1), plays an important role in cell elongation in Arabidopsis [39]. Only one gene of CTRI (Ntabacum_ESTC012515) was detected, and its expression is suppressed approximately 4.59-fold in RLK1ox cells compared to BY-2 cells (Table S2). This suppressed expression of the CTRl gene may contribute to reducing cell elongation and cell size in RLK1ox cells.

Cell wall-modifying proteins, including PGs and EXPs, cooperatively disassemble wall polysaccharide networks in tomato fruit. The pg/exp fruit were observed to be firmer and had denser cell walls than fruit of the other genotypes [9]. Recently, the endo-PG Polygalacturonase involved in expansion1 ( $P G X 1)$ was shown to be involved in hypocotyl elongation and cell expansion [40]. Lower expression of $P G$ genes may be associated with the fact that RLK1ox cells are smaller than BY-2 cells.

Expansins, as cell wall proteins, mediate acid-induced growth by catalyzing the loosening of plant cell walls without lysis of cell wall polymers. In other words, expansins have an essential role in cell wall-loosening activity to promote plant cell elongation and expansion under various conditions by binding to complex cell walls. RLK1ox cells proliferate more 
quickly than BY-2 cells $[27,28]$. Decreases in the expression of 6 EXPA genes and 6 EXLB genes indicate that the RLK1ox cells are less expandable and elongated than the BY-2 cells, and that the cell wall thickness of the RLK1ox cells is narrower than that of the BY-2 cells (Fig. 8). This result indicates why RLK1ox cells are smaller than BY-2 cells. In addition, we suggest that the decreases in the expression of both EXP genes and $P G$ genes cause the cell walls of RLK1ox cells to be thinner than those of BY-2 cells (Fig. 1, 2, and 6).

The simultaneous suppression of $P G$ genes, EXPA genes, and $E X P B 1$ genes can reduce cell wall disassembly; RLK1ox cells are more compact, have fewer cell wall components and neutral sugar contents, and have thinner cell walls than BY-2 cells (Fig. 2 and 3). It is not excluded the possibility that the protoplasts collections may have different distributions of cell cycle stages and this may account for the differences in cell size because cell doubling time was affected by ectopic expression of CaRLK1 gene [27].

\section{Conclusion}

Ectopic expression of the CaRLK1 gene make cell size smaller and cell wall thinner. Smaller cell size of the RLK1ox cells is related with suppressed cell expansion. It was showed that exogenous expansins induced BY-2 cell growth (cell expansion) 3-fold [41]. However, ectopic expression of the CaRLK1 gene suppressed not only the expression of 12 EXPA genes and $6 E X L B$ genes but also that of $2 A C S$ genes and $5 A C O$ genes. But the highly induced expressions of 7 GA2ox genes can inactivate precursor and active gibberellins in the RLK1ox cell, suggesting that ectopic expression of the CaRLK1 gene suppress cell growth and expansion. These results support the fact that the RLK1ox cell is less expandable than the BY2 cell.

A smaller cell is more effective and transporting materials, including oxygen, nutrients, and waste products, than a larger cell. That is, the larger a cell gets, the more difficult it is for 
nutrients and gases to move in and out of the cell. Thus, RLK1ox cells can better take up sufficient nutrients and oxygen to service their cell volume than wild-type, because their cell size is smaller and their cell wall is thinner than BY-2 cells'.

We postulate that RLK1ox cells may compete in producing proteins more than wildtype cells based on such characteristics as smaller cell size, fast dividing characteristic, and powerful proliferation because it is well known that BY-2 cells can be used as host cells for the large-scale production of recombinant proteins [45].

\section{Methods}

\section{Cell Cultures and Growth Conditions}

Wild-type and two transgenic Nicotiana tabacum L. cv Bright Yellow 2 (BY-2) cell lines were mainly used in the studies [27]. The BY-2 suspension cell cultures were maintained in modified liquid MS media [4.4 g/L MS vitamin and salts, $30 \mathrm{~g} / \mathrm{L}$ sucrose, $0.21 \mathrm{~g} / \mathrm{L}$ potassium phosphate monobasic, $0.2 \mathrm{mg} / \mathrm{L}$ 2,4-dichlorophenoxyacetic acid (2,4-D), $\mathrm{pH} 5.7]$ on a rotary shaker $(130 \mathrm{rpm})$ at $25{ }^{\circ} \mathrm{C}$ in the dark and were subcultured weekly $(1: 10$ or $1: 20)$ into fresh culture media $[27,28]$. Wild-type BY-2, transgenic BYK vector control cell, and transgenic tobacco cell lines (RLK10x) were also used to conduct the studies [28]. These calli were maintained in solid media at $25{ }^{\circ} \mathrm{C}$ in the dark and were subcultured every two weeks into fresh solid culture media. Most of the experiments were performed using cells in exponential growth phase.

\section{Protoplast isolation and measurement of diameter}

A 6-day-old tobacco suspension cell of BY-2 and RLK1ox was treated with a cell wall- 
degrading enzyme mixture (1\% Cellulase R10, 0.25\% Macerozyme R-10, 0.2\% Pectolyase Y23 and $0.2 \%$ Driselase) from Basidiomycete sp. in protoplast culture medium $\left(4.3 \mathrm{~g} \mathrm{~L}^{-1} \mathrm{MS}\right.$

salts, $0.4 \mathrm{M}$ sucrose (13.7\%), $500 \mathrm{mg} \mathrm{L}^{-1} \mathrm{MES}$ hydrate, $750 \mathrm{mg} \mathrm{L}{ }^{-1} \mathrm{CaCl}_{2} \cdot 2 \mathrm{H}_{2} \mathrm{O}$ and $250 \mathrm{mg}$ $\mathrm{L}^{-1} \mathrm{NH}_{4} \mathrm{NO}_{3}, \mathrm{pH}$ 5.7) to remove their cell walls at $30^{\circ} \mathrm{C}$ for more than $2 \mathrm{~h}$ with gentle shaking in the dark. The resulting protoplasts were almost spherical in shape. Protoplasts were collected through a $100-\mu \mathrm{m}$ cell strainer (Thermo Fisher, USA) and washed 3 times by flotation $(80 \times \mathrm{g}$, $10 \mathrm{~min}$ ). Then, over 491 cells were counted and analyzed on a hemocytometer; the protoplasts were photographed, and their diameters were measured.

\section{Transmission electron microscopy (TEM)}

For TEM analysis to measure cell wall thickness [42], suspension cells were grown for 7 days at $25^{\circ} \mathrm{C}$, and samples were taken and fixed with a mixture of fresh $2 \%$ glutaraldehyde (v/v) and 2\% paraformaldehyde (v/v) in $50 \mathrm{mM}$ cacodylate buffer ( $\mathrm{pH} 7.2)$ at RT for $4 \mathrm{~h}$. After washing, the samples were postfixed with $1 \%$ osmium tetroxide in $50 \mathrm{mM}$ cacodylate buffer at RT for $1 \mathrm{~h}$. After serial dehydration with ethanol, the samples were infiltrated with a mixture of ethanol and London Resin White (LR White) (London Resin Co., London, UK). After substitution with an ascending LR White series, the samples were embedded in LR White. Ultrathin sections $(80 \mathrm{~nm})$, which were prepared with an ultramicrotome equipped with a diamond knife and mounted on uncoated nickel grids (300 mesh), were stained with $4 \%$ uranyl acetate and $1 \%$ lead citrate. The sections were observed with a JEM-1400 TEM (JEOL Ltd.) at an acceleration voltage of $80 \mathrm{kV}$. Cell wall thickness was calculated with the iTEM image analysis program (Olympus Soft Imaging Solution $\mathrm{GmbH}$ ).

\section{Neutral sugar analysis by gas chromatography}

The neutral sugar contents were analyzed using a modified alditol acetate method [43]. 
The cell wall, isolated with acetone and distilled water, was treated with $72 \%$ sulfuric acid at RT for $45 \mathrm{~min}$ and diluted with water to $4 \%$ sulfuric acid. After hydrolysis for $1 \mathrm{~h}$ at $121{ }^{\circ} \mathrm{C}$, the solution was neutralized with ammonia solution. After myo-inositol was added as an internal standard, an aliquot was reduced using $2 \%$ sodium tetrahydroborate. Alditol was acetylated with a catalyst (methylimidazole) followed by acetic anhydride, and it was then extracted with dichloromethane. Gas chromatography (CP-9100, Chrompack, the Netherlands) was performed using a DB-225 capillary column (30 $\mathrm{m}$ x $0.25 \mathrm{~mm}$ i.d., $0.25-\mu \mathrm{m}$ film thickness, $\mathrm{J} \& \mathrm{~W})$ and a flame ionization detector. The operating conditions were as follows: detector temperature, $250{ }^{\circ} \mathrm{C}$; injector temperature, $220^{\circ} \mathrm{C}$; oven temperature rose from 100 (1.5 min) to $220^{\circ} \mathrm{C}$ at a rate of $5^{\circ} \mathrm{C} \cdot \mathrm{min}^{-1}$. Compounds were identified by comparing retention times of standard compounds.

\section{Quantitative real-time PCR (qRT-PCR) analysis}

Purified total RNA $(1 \mu \mathrm{g})$ was used for first-strand cDNA synthesis with oligo d(T) $)_{18}$ and reverse transcriptase according to the manufacturer's instructions (PhileKorea Technology, Korea) [28]. Experimental samples were evaluated in triplicate, and qRT-PCR reactions for each sample were run in duplicate. PCR was conducted using a LightCycler ${ }^{\circledR} 480$ II Real Time PCR Instrument (Roche Diagnostics $\mathrm{GmbH}$ ) in a total volume of $20 \mu \mathrm{L}$ containing $4 \mu \mathrm{L}$ of cDNA ( $<50 \mathrm{ng}), 1.0 \mu \mathrm{L}$ of forward and reverse primer mix $(5 \mu \mathrm{M}$ each), and $10 \mu \mathrm{L}$ of $2 \mathrm{x}$ HotSybr Real-time PCR Mix (PhileKorea Technology, Korea). PCR amplification was performed under the following conditions: preincubation at $95^{\circ} \mathrm{C}$ for $5 \mathrm{~min}$ and 45 cycles of 15 $\mathrm{s}$ at $95^{\circ} \mathrm{C}, 20 \mathrm{~s}$ at $55^{\circ} \mathrm{C}$ and $20 \mathrm{~s}$ at $72^{\circ} \mathrm{C}$. After each run, a melting curve was examined for a single product amplification. The qRT-PCR data were analyzed by the comparative $\mathrm{C}_{\mathrm{T}}$ method

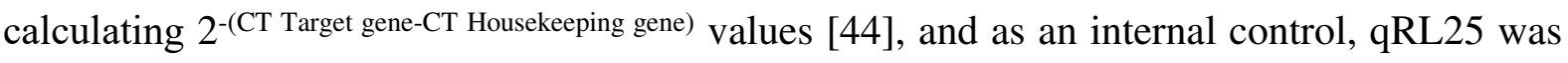


selected for data normalization. The nucleotide sequences of other primers are listed in Table SI.

\section{Microarray analysis}

Expression profiling was conducted using a tobacco 3'-Tiling microarray containing 34,052 consensus sequences that were deposited into the National Center for Biotechnology Information database (NCBI; http://www.ncbi.nlm.nih.gov/). The microarray data sets used in this study can be found at www.ncbi.nlm.nih.gov/geo/ (Gene Expression Omnibus, GEO). The NCBI accession number is GSE47671 [27].

\section{RT-PCR analysis}

The frozen cells were ground in liquid nitrogen and kept frozen. Total RNA was extracted from cultured calli or plants using TRIzol reagent (Invitrogen, Carlsbad, CA, USA) $[27,28]$. First-strand cDNA synthesis was performed with $2 \mu \mathrm{g}$ of total RNA and an oligo (dT) primer using SuperScript II Reverse Transcriptase (Invitrogen) according to the manufacturer's recommendations. For the semiquantitative PCR analysis, Taq polymerase was used. Amplification was performed using cycles of $95^{\circ} \mathrm{C}$ for $15 \mathrm{~s}, 57^{\circ} \mathrm{C}$ for $20 \mathrm{~s}$, and $72^{\circ} \mathrm{C}$ for $30 \mathrm{~s}$. The PCR products were electrophoresed on $1.2 \%$ agarose gels in the presence of ethidium bromide $\left(0.5 \mathrm{mg} \cdot \mathrm{L}^{-1}\right)$. Each PCR was performed at least 3 times with different cDNA sets and primers (Table S1).

\section{List of abbreviations}

ABA, abscisic acid; AD, average diameter; BL, brassinolide; ACO, 1-aminocyclopropene-1carboxylic acid oxidase; ACS, 1-aminocyclopropene-1-carboxylic acid synthase; BY-2, 
Nicotiana tabacum L. cv Bright Yellow 2 cell; BYK, BY-2 vector control cell; CaRLK1, Capsicum annuum receptor-like kinase 1; CESA, cellulose synthase A; CSC, cellulose synthase complex; DD, diameter distribution; EXPA, expansin A; EXLB, expansin-like B; GA, gibberellin; GA2ox, gibberellin 2-oxidase; GA20ox, GA 20-oxidase; GA3ox, GA 3-oxidase; GMMT, glucomannan 4- $\beta$-mannosyltransferase; IAA, indole-3-acetic acid; MJ, methyl jasmonate; MS, Murashige and Skoog; PCW, primary cell wall; PG, polygalacturonase; RLK1ox, CaRLK1 overexpression; SCW, secondary cell wall; SUS1, sucrose synthase 1; TEM, transmission electron microscopy; 2,4-D, 2,4-dichlorophenoxyacetic acid

\section{Declarations}

\section{Ethics approval and consent to participate}

Not applicable.

\section{Consent for publication}

Not applicable.

\section{Availability of data and materials}

Datasets used in the current study are available from the corresponding author on reasonable request.

\section{Competing interests}

The authors declare that they have no competing interests.

\section{Funding}

This research was supported by the Basic Science Research Program through the National Research Foundation of Korea (NRF) funded by the Ministry of Education (grant number 2017R1D1A1B03035792), awarded to Dong Ju Lee.

\section{Author Contributions}


DJL conceived the study, designed the experiments, analyzed the microarray data, and wrote the manuscript. I-CK designed the experiments. SJ did qRT-PCR experiments, SGW analyzed neutral sugar contents, WSA and SWK measured protoplast size.

\section{Acknowledgments}

We thank Dr. Yang-Gyu Ku for his help to analyze statistics.

\section{Footnotes}

Not applicable.

\section{References}

1. Marshall WF, Young KD, Swaffer M, Wood E, Nurse P, Kimura A, Frankel J, Wallingford J, Walbot V, Qu X, and Roeder AHK. What determines cell size? BMC Biology 2012;10:101.

2. Willis L et al. Cell size and growth regulation in the Arabidopsis thaliana apical stem cell niche. Proc Natl Acad Sci USA. 2016;113(51):E8238-E8246.

3. Cosgrove DJ. Plant expansins: diversity and interactions with plant cell walls. Curr Opin Plant Biol. 2015;25:162-72.

4. Cosgrove DJ. Plant cell wall extensibility: connecting plant cell growth with cell wall structure, mechanics, and the action of wall modifying enzymes. J. Exp. Bot. 2016;67(2):463476.

5. Veytsman BA, Cosgrove DJ. A model of cell wall expansion based on thermodynamics of polymer networks. Biophysical J. 1998;75(5):2240-2250.

6. Bashline L, Li S, Gu Y. The trafficking of the cellulose synthase complex in higher plants. Annals of Botany 2014;114(6):1059-1067.

7. Endler A, Persson S. Cellulose synthases and synthesis in arabidopsis. Molecular Plant 2011;4:199-211.

8. Catalá C, Rose JKC, Bennett AB. Auxin-regulated genes encoding cell wall-modifying 
proteins are expressed during early tomato fruit growth. Plant Physiol. 2000;122(2):527-534.

9. Jiang F et al. Disassembly of the fruit cell wall by the ripening-associated polygalacturonase and expansin influences tomato cracking. Horticulture Research 2019;6: Article 17.

10. Cho HT, Kende H. Tissue localization of expansins in deepwater rice. Plant J. 1998; 15(6):805-812.

11. Colmer TD, Peeters AJM, Wagemaker CAM, Vriezen WH, Ammerlaan A, Voesenek LACJ. Expression of $\alpha$-expansin genes during root acclimations to $\mathrm{O}_{2}$ deficiency in Rumex palustris. Plant Mol Biol. 2004;56:423-437.

12. Mayorga-Gómez A, Nambeesan SU. Temporal expression patterns of fruit-specific $\alpha-$ EXPANSINS during cell expansion in bell pepper (Capsicum annuum L.). BMC Plant Biology 2020;20: Article 241.

13. Lee $Y$, Kende H. Expression of $\alpha$-expansin and expansin-like genes in deepwater rice. Plant Physiol. 2002;130:1396-1405.

14. Lee Y, Choi D, Kende H. Expansins: ever-expanding numbers and functions. Curr Opin Plant Biol. 2001;4(6):527-532.

15. Kuluev B, Avalbaev A, Mikhaylova E, Nikonorov Y, Berezhneva Z, Chemeris A. Expression profiles and hormonal regulation of tobacco expansin genes and their involvement in abiotic stress response. J Plant Physiol. 2016;206:1-12.

16. Vriezen WH, De Graaf B, Mariani C, Voesenek LACJ. Submergence induces expansin gene expression in flooding-tolerant Rumex palustris and not in flooding-intolerant $R$. acetosa. Planta 2000;210:956-963.

17. Cho HT, Cosgrove DJ. Regulation of root hair initiation and expansin gene expression in Arabidopsis. Plant Cell 2002;14:3237-3253.

18. Garg R, Tyagi AK, Jain M. Microarray analysis reveals overlapping and specific transcriptional responses to different plant hormones in rice. Plant Signal Behav. 2012;7:951- 
956.

19. Xu Q, Krishnan S, Merewitz E, Xu J, Huang B. Gibberellin-regulation and genetic variations in leaf elongation for tall fescue in association with differential gene expression controlling cell expansion. Sci Rep. 2016;6:30258.

20. Robert AM et al. Ethylene regulates fast apoplastic acidification and expansin A transcription during submergence-induced petiole elongation in Rumex palustris. Plant J. 2005;3:597-610.

21. Vreeburg RA et al. Ethylene regulates fast apoplastic acidification and expansin A transcription during submergence-induced petiole elongation in Rumex palustris. Plant J. 2005;43(4):597-610.

22. Wang KLC, Li H, Ecker JR. Ethylene biosynthesis and signaling networks. Plant Cell. 2002; S131-S151.

23. Lee DJ, Zeevaart JA. Molecular cloning of GA 2-oxidase3 from spinach and its ectopic expression in Nicotiana sylvestris. Plant Physiol. 2005;138(1):243-254.

24. Lee DJ, Zeevaart JA. Regulation of gibberellin 20-oxidase1 expression in spinach by photoperiod. Planta 2007;226:35-44.

25. Nagata T, Nemoto Y, Hasezawa S. Tobacco BY-2 cell line as the Hela cell in the cell biology of higher plants. Int Rev Cytol. 1992;132:1-30.

26. Yi SY, Lee DJ, Yeom SI, Yoon J, Kim YH, Kwon SY, Choi D. A novel pepper (Capsicum annuиm) receptor-like kinase functions as a negative regulator of plant cell death via accumulation of superoxide anions. New Phytol. 2010;185(3):701-715.

27. Lee DJ, Chi YT, Kim DM, Choi SH, Lee JY, Choi GW. Ectopic expression of CaRLK1 enhances hypoxia tolerance with increasing alanine production in Nicotiana spp. Plant Mol Biol. 2014;86:255-270.

28. Lee DJ, Choi HJ, Moon ME, Chi YT, Ji KY, Choi D. Superoxide serves as a putative signal 
molecule for plant cell division: overexpression of CaRLK1 promotes the plant cell cycle via accumulation of $\mathrm{O}_{2}{ }^{-}$and decrease in $\mathrm{H}_{2} \mathrm{O}_{2}$. Physiol Plant. 2017;159(2):228-243.

29. Suzuki M, Igarashi R, Sekiya M, Utsugi T, Morishita S, Yukawa M, Ohya Y. Dynactin is involved in a checkpoint to monitor cell wall synthesis in Saccharomyces cerevisiae. Nat Cell Biol. 2004;6(9):861-871.

30. Yang Y, Yu Y, Liang Y, Anderson CT, Cao J. A profusion of molecular scissors for pectins: classification, expression, and functions of plant polygalacturonases. Front. Plant Sci. 2018; 9: Article 1208.

31. Attia MA, Brumer H. Recent structural insights into the enzymology of the ubiquitous plant cell wall glycan xyloglucan. Cur Opi Str Biol. 2016;40:43-53.

32. Ding A, Marowa P, Kong Y. Genome-wide identification of the expansin gene family in tobacco (Nicotiana tabacum). Mol Genet Genomics 2016;291:1891-1907.

33. Krishnamurthy P, Muthusamy M, Kim JA, Jeong M-J, Lee SI. Brassica rapa expansin-like B1 gene (BrEXLB1) regulate growth and development in transgenic Arabidopsis and elicits response to abiotic stresses. J Plant Biochem Biotech. 2019;28(4):437-446.

34. Persson S, Paredez A, Carroll A, Palsdottir H, Doblin M, Poindexter P, Khitrov N, Auer M, Somerville CR. Genetic evidence for three unique components in primary cell-wall cellulose synthase complexes in Arabidopsis. Proc Natl Acad Sci USA. 2007;104:15566-15571.

35. Amor Y, Haigler CH, Johnson S, Wainscott M, Delmer DP. A membrane-associated form of sucrose synthase and its potential role in synthesis of cellulose and callose in plants. Proc Natl Acad Sci USA. 1995;92:9353-9357.

36. Fujii S, Hayashi T, Mizuno K. Sucrose synthase is an integral component of the cellulose synthesis machinery. Plant and Cell Physiol. 2010;51(2):294-301.

37. Siciliano I et al. Expression of arabidopsis WEE1 in tobacco induces unexpected 
morphological and developmental changes. Sci Rep. 2019;9:8695.

38. Polko JK, van Zanten M, van Rooij JA, Marée AF, Voesenek LA, Peeters AJ, Pierik R. Ethylene-induced differential petiole growth in Arabidopsis thaliana involves local microtubule reorientation and cell expansion. New Phytol. 2012;193(2):339-348.

39. Kieber JJ, Rothenberg M, Roman G, Feldmann KA, Ecker JR. CTR1, a negative regulator of the ethylene response pathway in Arabidopsis, encodes a member of the raf family of protein kinases. Cell 1993;72(3):427-441.

40. Xiao C, Somerville C, Anderson CT. Polygalacturonase involved in expansion1 functions in cell elongation and flower development in Arabidopsis. Plant Cell. 2014;26(3):1018-1035. 41. Link BM and Cosgrove DJ. Acid-growth response and a-expansins in suspension cultures of Bright Yellow 2 Tobacco cells. Plant Physiol. 1998;118:907-916.

42. Martín-Cuadrado AB et al. Role of septins and the exocyst complex in the function of hydrolytic enzymes responsible for fission yeast cell separation. Mol Biol Cell. 2005;16:48674881.

43. Blakeney AB, Harris PJ, Henry RJ, Stone BA. A simple and rapid preparation of alditol acetates for monosaccharide analysis. Carbohydr Res. 1983;113:291-299.

44. Schmittgen TD, Livak KJ. Analyzing real-time PCR data by the comparative CT method. Nat Protoc. 2008;3:1101-1108.

45. Häkkinen ST, Reuter L, Nuorti N, Joensuu JJ, Rischer H, Ritala A. Tobacco BY-2 media component optimization for a cost-efficient recombinant protein production. Frontiers in Plant Science 2018; 9: Article 45.

\section{Legends to figures}

Figure 1. Effect of CaRLK1 overexpression on protoplast size. A. average diameter comparison of protoplasts prepared from BY-2 cells (white bars) and RLK1ox cells (black bars). The 
diameters of the circular protoplasts are determined from microscopy images. The average diameter of the RLK1ox protoplast is shorter than that of the BY-2 protoplasts. In vitro cell culture yielded protoplasts of BY-2 cells with the average diameters $(41.38 \mu \mathrm{m})$ and protoplasts of RLK1ox cells with the average diameters $(30.53 \mu \mathrm{m})$. Error bars represent standard error from the mean $(n \geq 500)$. The differences among the two conditions are significant $(\mathrm{P}<0.05)$. B. Distribution of protoplast size. Cell size distribution can be enumerated by image analysis. The range of size distribution estimated from the light microscope. Protoplasts were mounted on a Fuchs-Rosenthal counting chamber of hemocytometer for measurements.

Figure 2. Effect of $C a R L K 1$ overexpression on plant cell wall thickness. A. Quantification of cell wall thickness in double layer between adjoining cells of wild-type BY-2 cells $(n=57)$ and of RLK1ox cells $(n=41)$. The differences among the two conditions are significant $(\mathrm{P}<0.05)$. B. TEM micrographs of cross sections between adjoining cells. C. Quantification of cell wall thickness in single layer of wild-type BY-2 cells $(n=57)$ and RLK1ox cells $(n=55)$. The differences among the two conditions are significant $(\mathrm{P}<0.05)$. D. TEM micrographs of cross sections of one cell wall layer. After incubated on solid BY-2 medium for 4 weeks, cells were harvested and processed for TEM, and ultrathin sections $(80 \mathrm{~nm})$ were prepared with an ultramicrotome equipped with a diamond knife. Transmission electron microscopic pictures of cell wall were taken before the quantification. White arrows indicate the cell wall. C; cytoplasmic side. O; outside of cells.

Figure 3. Effect of CaRLK1 overexpression on cell wall sugar components. Neutral sugar contents from purified cell wall of BY-2 and RLK1ox cell were quantified. The RLK1ox cells 
have less amount of cell wall components than BY-2 cells. Error bars represent standard error from the mean $(n=3)$. The differences among the two conditions are significant $(\mathrm{P}<0.05)$.

Figure 4. Expression analysis of CESA genes between BY-2 cells and RLK1ox cell. It was used Nicotiana tabacum 135K 3'-Tiling microarray chips manufactured by NimbleGen. The expression levels of seven genes encoding cellulose synthase (CESA) are lower in experimental group (RLK1ox) than the control (BY-2), respectively. Each sample was harvested from 3-days old culture. Error bars represent standard error from the mean $(n=3)$.

Figure 5. Comparison of expressions of glucomannan 4- $\beta$-mannosyltransferase (GMMT) genes (A) and mannose-1-phosphate guanyltransferase genes (B) between BY-2 cell and RLK1ox cell. Mannose-1-phosphate guanyltransferase produces GDP-mannose, a substrate for glucomannan 4- $\beta$-mannosyltransferase, glucomannan synthesis enzyme. Each sample was harvested from 3-days old culture. Error bars represent standard error from the mean $(n=3)$.

Figure 6. Comparison of expressions of polygalacturonase (PG) genes between BY-2 cells and RLK1ox cells. The expressions of 14 PG genes, as a pectinase, decreased in RLK1ox cells. Each sample was harvested from 3-days old culture. Error bars represent standard error from the mean $(n=3)$.

Figure 7. Comparison of expressions of gibberellin 2-oxidase (GA2ox) genes between BY-2 cells and RLK1ox cells. (A) The microarray analysis of GA2ox genes. The expression levels of 4 GA2ox genes greatly increased in RLK1ox cells. Error bars represent standard error from the mean $(n=3)$. Quantitative real-time PCR analysis of expression levels of the GA2ox2 gene (B) and the GA2ox3 gene(C). Each samples were harvested from 3-days old culture. The 
differences among the two conditions for GA2ox2 and GA2ox3 are significant $(\mathrm{P}<0.05)$. The relative mRNA levels normalized to that of the ribosomal large subunit L25 gene and the s.e.m.is shown.

Figure 8. Comparison of expressions of expansin genes between BY-2 cells and RLK1ox cells. (A) The microarray analysis of expansin A genes. The expressions of 10 EXPA genes were decreased more than two times-fold in RLK1ox cells. Error bars represent standard error from the mean $(n=3)$. Quantitative real-time PCR analysis of expression levels of the EXPA4 (B) and EXPA11-1 gene (C) in BY-2 cell and RLK1ox cells. (D) The microarray analysis of expansin-like B1 (EXLB1) genes. The expressions of 6 EXLB1genes strongly decreased in RLK1ox cells. (E) Quantitative real-time PCR analysis of expression levels of one EXLB1 gene. Each samples were harvested from 3-days old culture. The differences among the two conditions for EXPA11-1 and EXLB1 are significant $(\mathrm{P}<0.05)$. The relative mRNA levels normalized to that of the ribosomal large subunit L25 gene and the s.e.m.is shown.

Figure 9. Comparison of expressions of 1-aminocyclopropane-1-carboxylate synthase (ACS) genes and ACO genes between BY-2 cells and RLK1ox cells. (A) The microarray analysis of ACS genes. The expression levels of 2 ACS genes decreased in RLK1ox cells. (B) Quantitative real-time PCR analysis of expression level of one ACS gene (Ntabacum_ESTC002216). The differences among the two conditions are significant $(\mathrm{P}<0.05)$. (C) The microarray analysis of 1-aminocyclopropane-1-carboxylate oxidase (ACO) genes, ethylene-forming enzyme. The expression levels of one ACO gene (Ntabacum_ESTC020923) steeply decreased in RLK1ox cells. (D) Quantitative real-time PCR analysis of expression levels of the ACO gene. Each sample was harvested from 3-days old culture. Error bars represent standard error from the mean $(n=3)$. The differences among the two conditions are significant $(\mathrm{P}<0.01)$. The relative 
mRNA levels normalized to that of the ribosomal large subunit L25 gene and the s.e.m.is shown.

\section{Supplemental Figures}

Supplementary Figure 1. Comparison of expressions of sucrose synthase 1 (SUS1) genes between BY-2 cells and RLK1ox cells by the microarray analysis. The expression levels of 5 SUS genes decreased in RLK1ox cells. Each sample was harvested from 3-days old culture. Error bars represent standard error from the mean $(n=3)$.

Supplementary Figure 2. Expression of WEE1 kinase gene, a key regulator of cell cycle progression. B; BYK control cells, R; RLK1ox cells. Suspension cells were harvested at the indicated time points. For RT-PCR, first strand cDNA was synthesized from $2 \mu \mathrm{g}$ of total RNA and used for amplification by PCR. The nucleotide sequences of other primers are listed in Table S1.

Supplementary Figure 3. Expressions of SAM synthase, which produce S-adenosylmethione (SAM), a precursor for ethylene. Their expressions are slightly induced. Each sample was harvested from 3-days old culture. Error bars represent standard error from the mean $(n=3)$.

\section{Supplemental Table}

Supplementary Table 1. Primers for q RT-PCR and RT-PCR amplification.

Supplementary Table 2. Differences in the transcriptome between wild-type BY-2 cell and RLK1ox cell. 


\section{Figures}
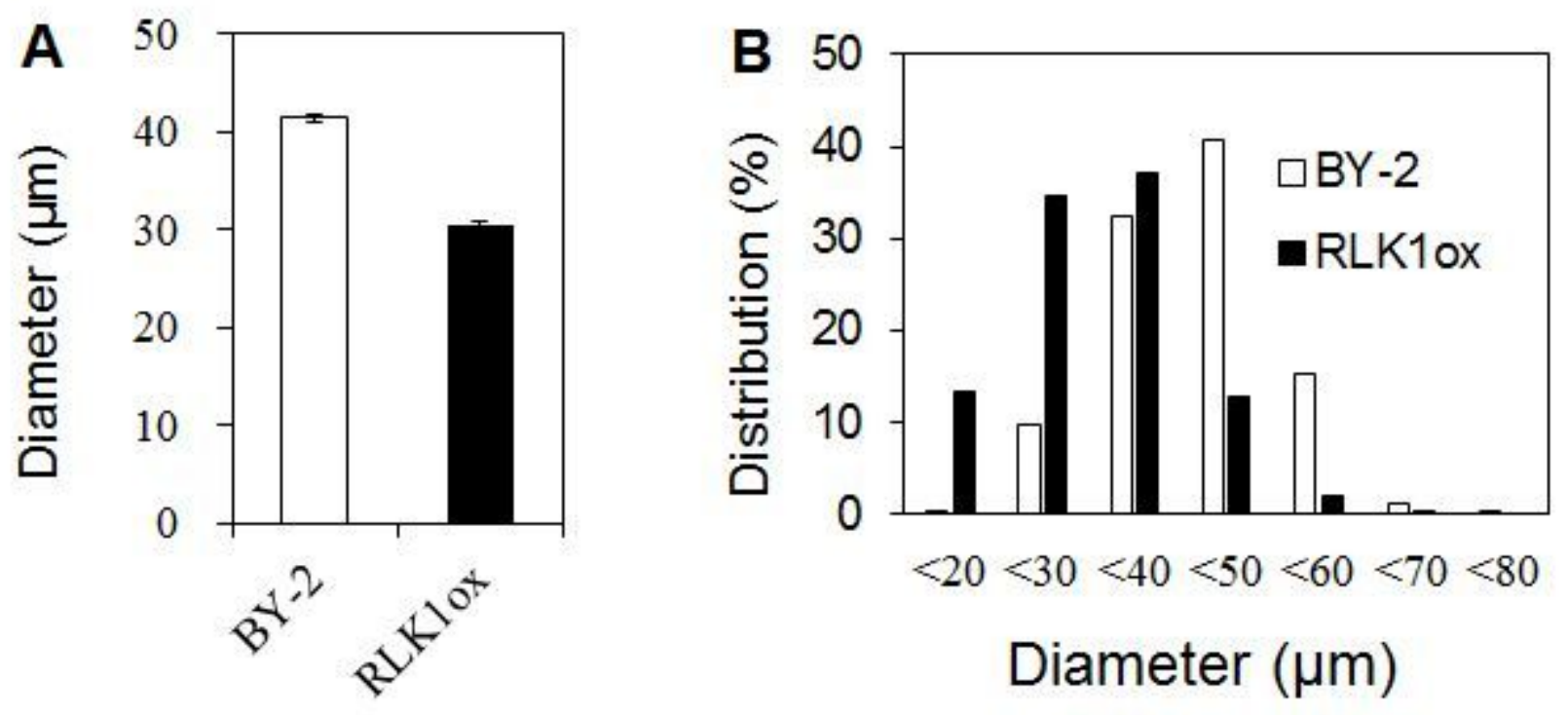

Figure 1

Effect of CaRLK1 overexpression on protoplast size. A. average diameter comparison of protoplasts prepared from BY-2 cells (white bars) and RLK1ox cells (black bars). The diameters of the circular protoplasts are determined from microscopy images. The average diameter of the RLK1 ox protoplast is shorter than that of the BY-2 protoplasts. In vitro cell culture yielded protoplasts of BY-2 cells with the average diameters $(41.38 \mu \mathrm{m})$ and protoplasts of RLK10x cells with the average diameters $(30.53 \mu \mathrm{m})$. Error bars represent standard error from the mean $(n \geq 500)$. The differences among the two conditions are significant $(P<0.05)$. B. Distribution of protoplast size. Cell size distribution can be enumerated by image analysis. The range of size distribution estimated from the light microscope. Protoplasts were mounted on a Fuchs-Rosenthal counting chamber of hemocytometer for measurements.

A

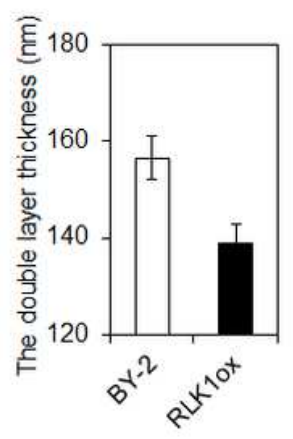

B

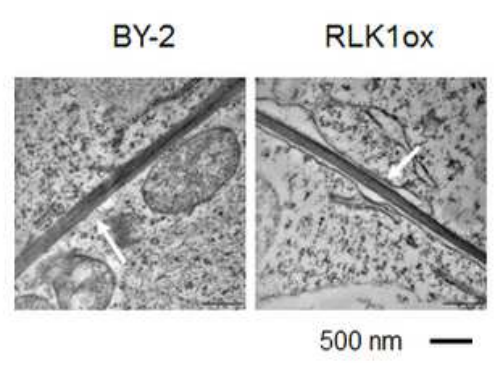

C

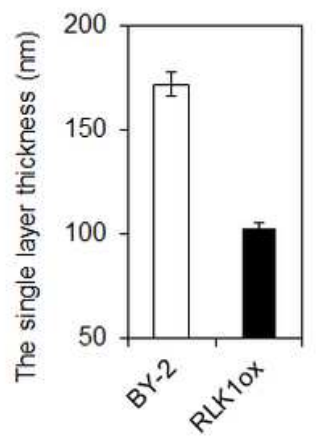

BY-2

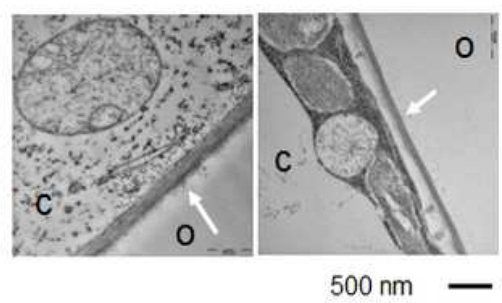

Figure 2 
Effect of CaRLK1 overexpression on plant cell wall thickness. A. Quantification of cell wall thickness in double layer between adjoining cells of wild-type BY-2 cells $(n=57)$ and of RLK1 ox cells $(n=41)$. The differences among the two conditions are significant $(P<0.05)$. B. TEM micrographs of cross sections between adjoining cells. C. Quantification of cell wall thickness in single layer of wild-type BY-2 cells $(n=57)$ and RLK1 ox cells $(n=55)$. The differences among the two conditions are significant $(P<0.05)$. D. TEM micrographs of cross sections of one cell wall layer. After incubated on solid BY-2 medium for 4 weeks, cells were harvested and processed for TEM, and ultrathin sections $(80 \mathrm{~nm})$ were prepared with an ultramicrotome equipped with a diamond knife. Transmission electron microscopic pictures of cell wall were taken before the quantification. White arrows indicate the cell wall. C; cytoplasmic side. O; outside of cells.

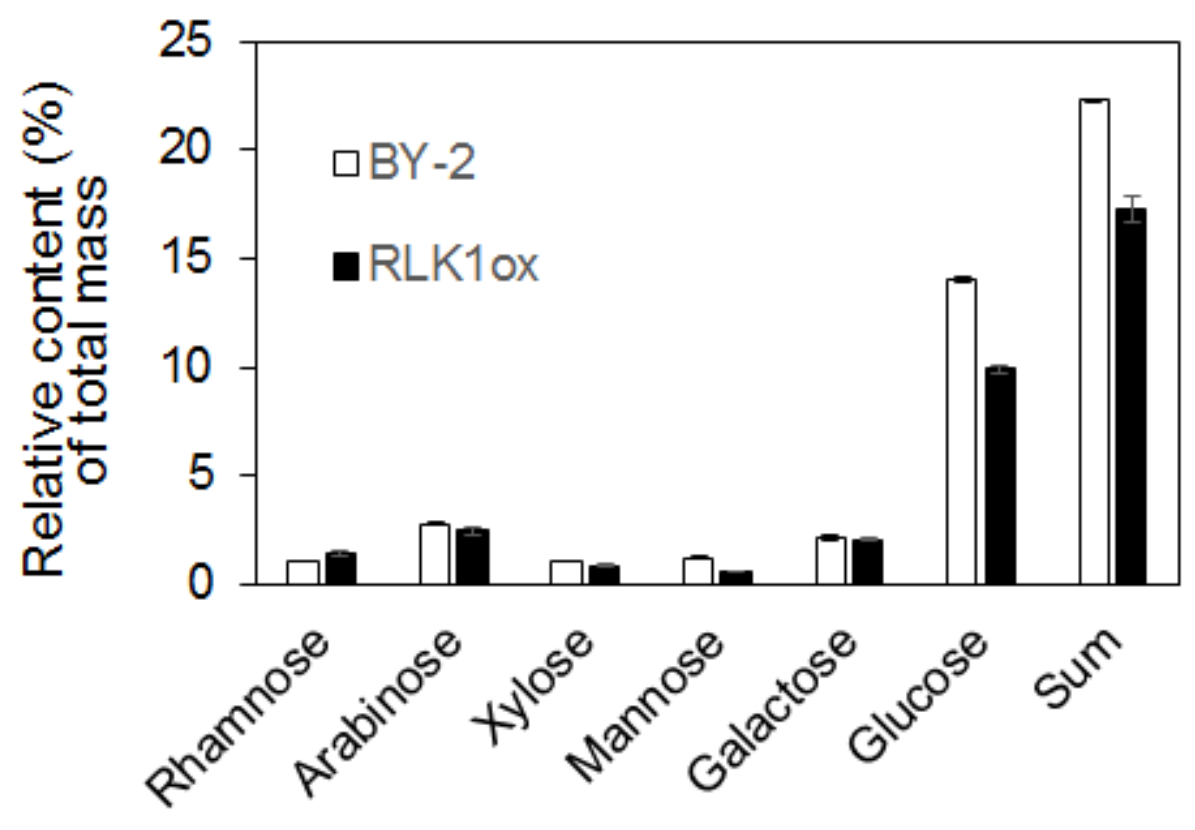

\section{Figure 3}

Effect of CaRLK1 overexpression on cell wall sugar components. Neutral sugar contents from purified cell wall of BY-2 and RLK1 ox cell were quantified. The RLK1ox cells have less amount of cell wall components than BY-2 cells. Error bars represent standard error from the mean $(n=3)$. The differences among the two conditions are significant $(\mathrm{P}<0.05)$. 


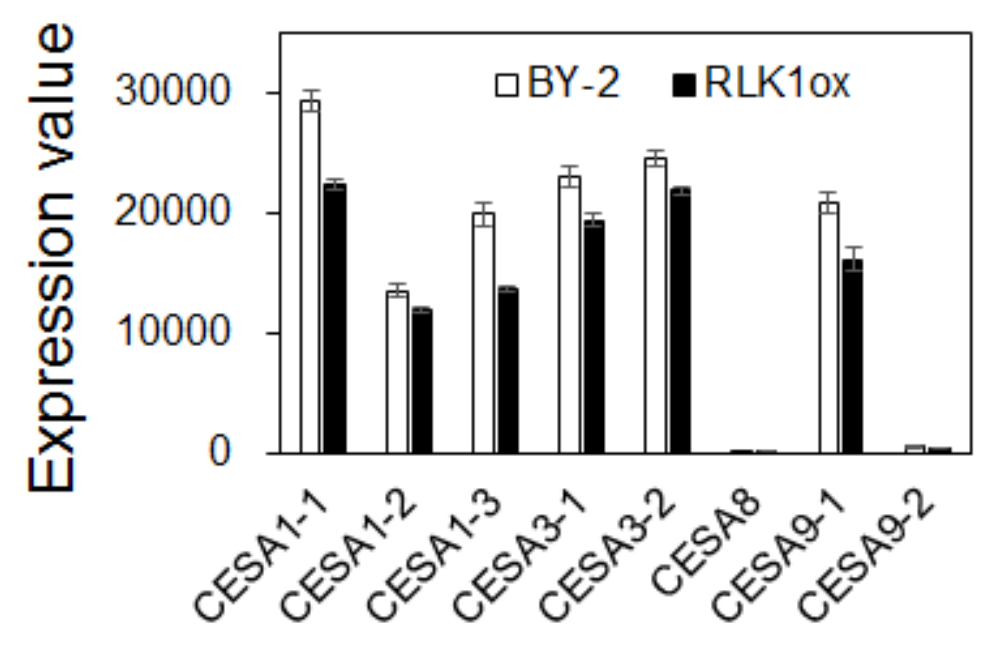

Figure 4

Expression analysis of CESA genes between BY-2 cells and RLK1 ox cell. It was used Nicotiana tabacum 135K 3'-Tiling microarray chips manufactured by NimbleGen. The expression levels of seven genes encoding cellulose synthase (CESA) are lower in experimental group (RLK1ox) than the control (BY-2), respectively. Each sample was harvested from 3-days old culture. Error bars represent standard error from the mean $(n=3)$.

A

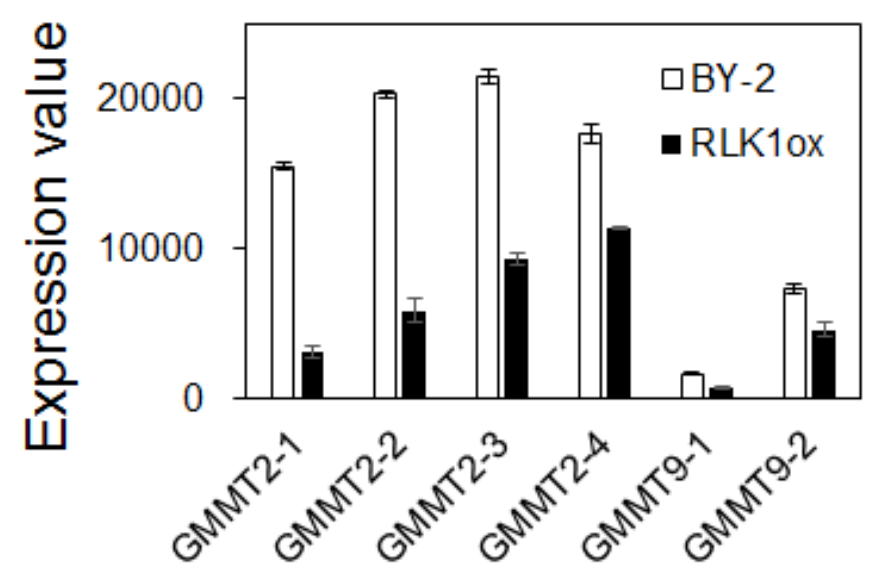

B

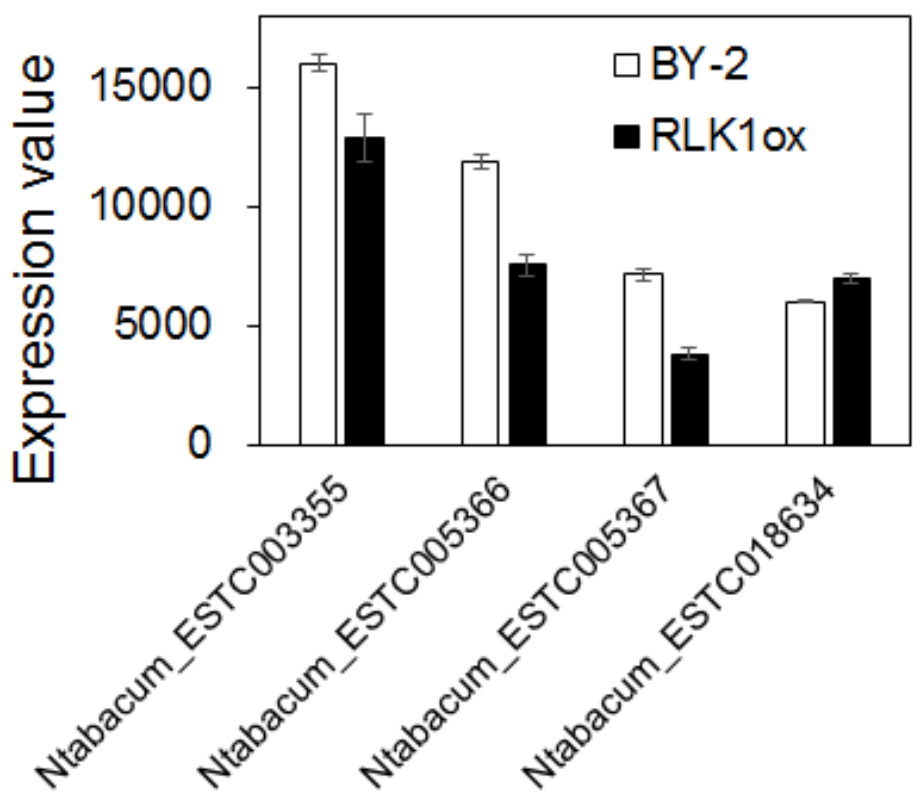

Figure 5

Comparison of expressions of glucomannan 4- $\beta$-mannosyltransferase (GMMT) genes (A) and mannose1-phosphate guanyltransferase genes (B) between BY-2 cell and RLK1ox cell. Mannose-1-phosphate 
guanyltransferase produces GDP-mannose, a substrate for glucomannan 4- $\beta$-mannosyltransferase, glucomannan synthesis enzyme. Each sample was harvested from 3-days old culture. Error bars represent standard error from the mean $(n=3)$.

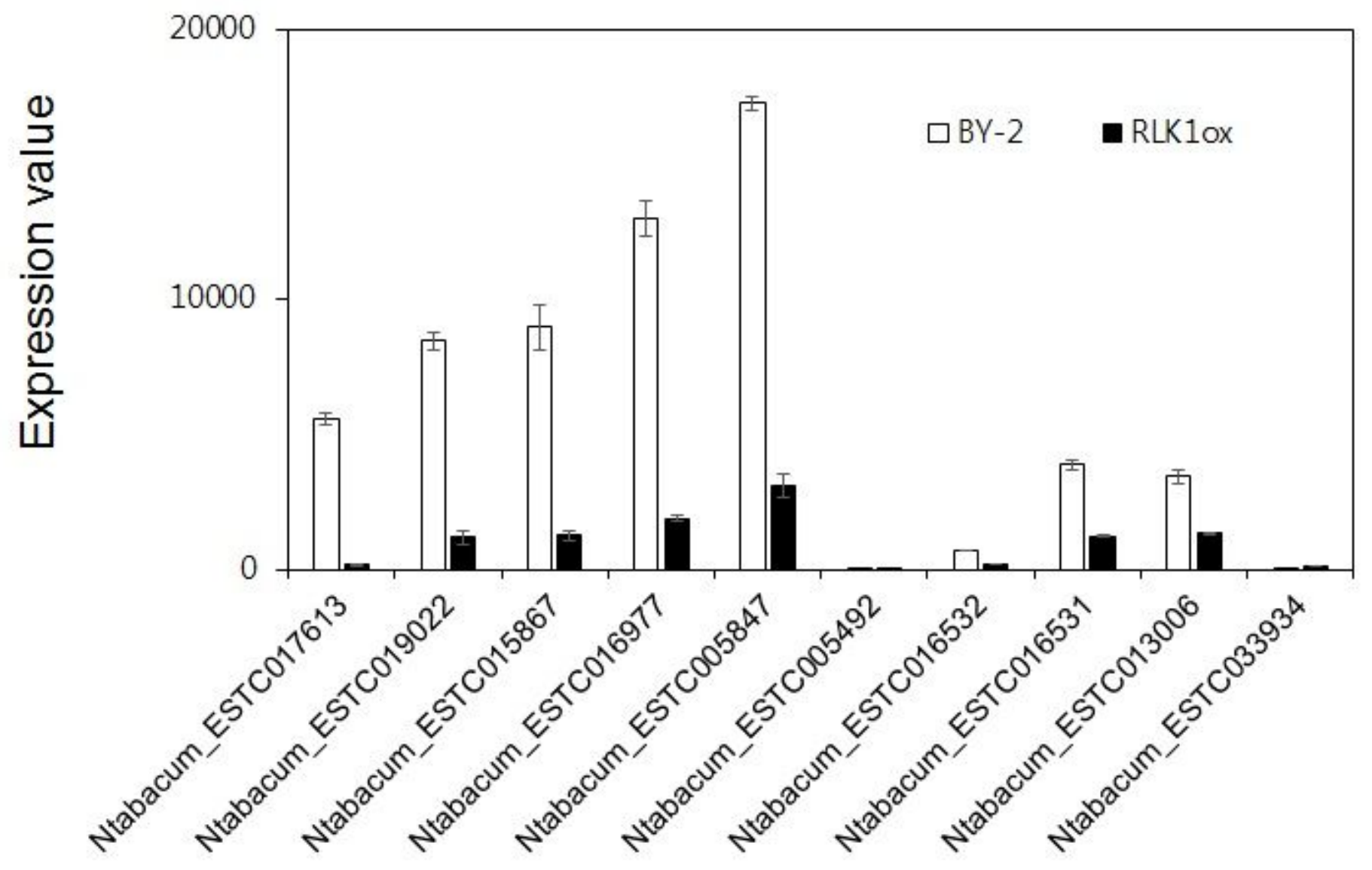

Figure 6

Comparison of expressions of polygalacturonase (PG) genes between BY-2 cells and RLK1ox cells. The expressions of 14 PG genes, as a pectinase, decreased in RLK1ox cells. Each sample was harvested from 3-days old culture. Error bars represent standard error from the mean $(n=3)$. 
A

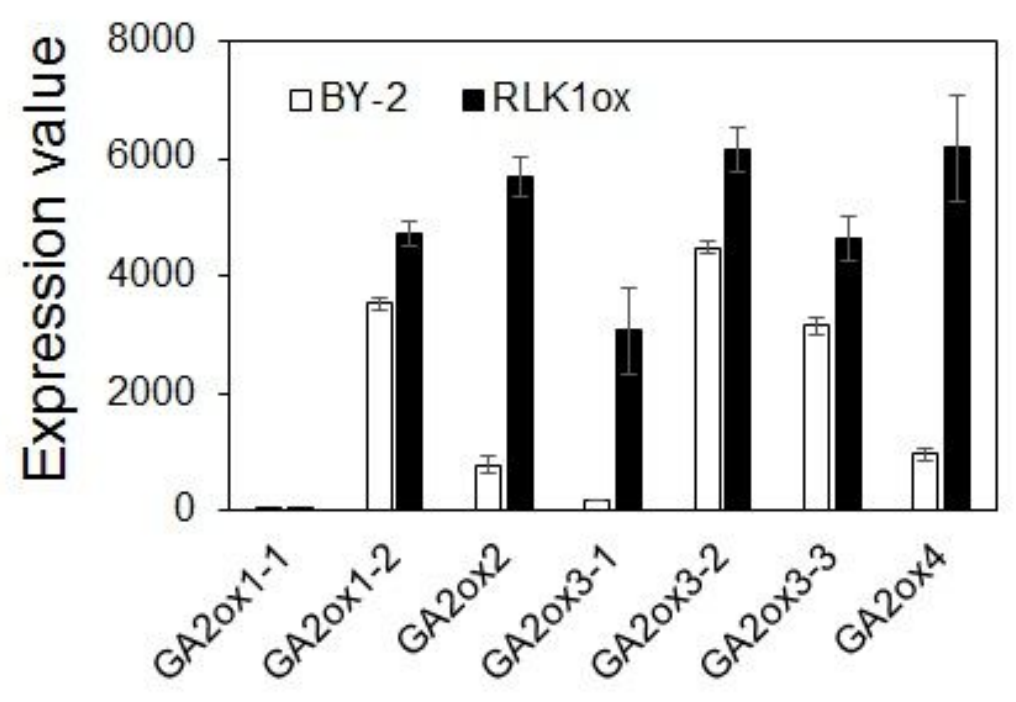

B

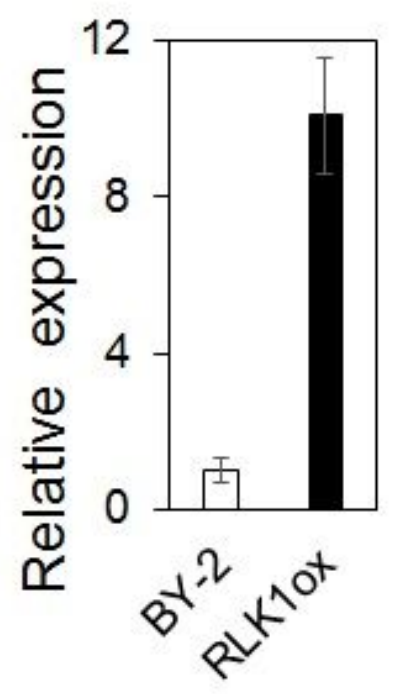

C

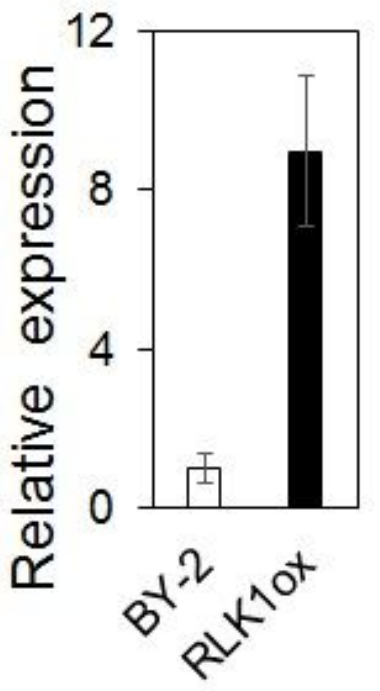

Figure 7

Comparison of expressions of gibberellin 2-oxidase (GA2ox) genes between BY-2 cells and RLK1ox cells. (A) The microarray analysis of GA2ox genes. The expression levels of 4 GA2ox genes greatly increased in RLK1 ox cells. Error bars represent standard error from the mean $(n=3)$. Quantitative real-time PCR analysis of expression levels of the GA2ox2 gene (B) and the GA2ox3 gene(C). Each samples were harvested from 3-days old culture. The differences among the two conditions for GA2ox2 and GA2ox3 are significant $(P<0.05)$. The relative mRNA levels normalized to that of the ribosomal large subunit L25 gene and the s.e.m.is shown. 

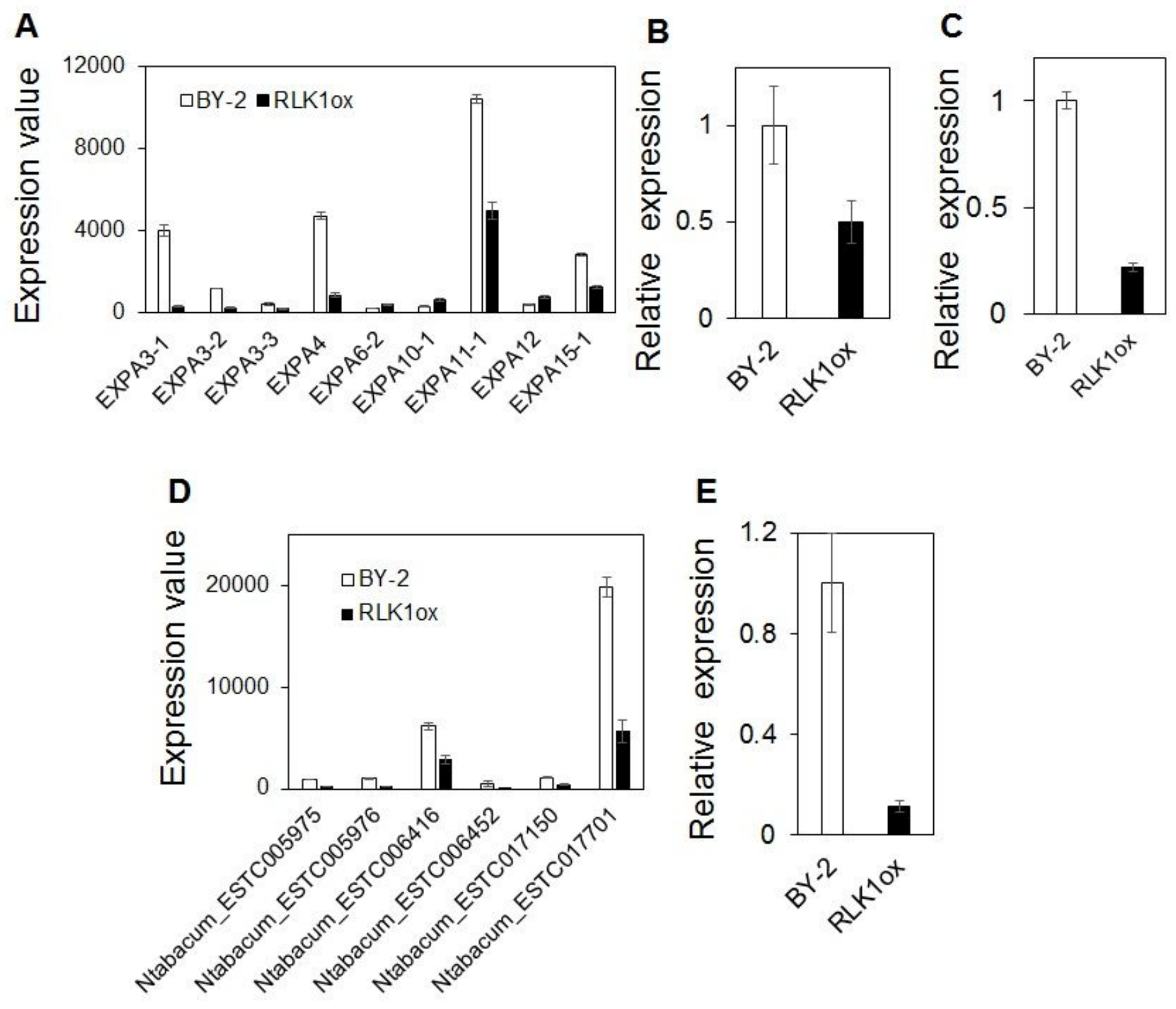

\section{Figure 8}

Comparison of expressions of expansin genes between BY-2 cells and RLK1ox cells. (A) The microarray analysis of expansin A genes. The expressions of 10 EXPA genes were decreased more than two timesfold in RLK1ox cells. Error bars represent standard error from the mean $(n=3)$. Quantitative real-time PCR analysis of expression levels of the EXPA4 (B) and EXPA11-1 gene (C) in BY-2 cell and RLK1 ox cells. (D) The microarray analysis of expansin-like B1 (EXLB1) genes. The expressions of 6 EXLB1genes strongly 
decreased in RLK1ox cells. (E) Quantitative real-time PCR analysis of expression levels of one EXLB1 gene. Each samples were harvested from 3-days old culture. The differences among the two conditions for EXPA11-1 and EXLB1 are significant $(P<0.05)$. The relative mRNA levels normalized to that of the ribosomal large subunit L25 gene and the s.e.m.is shown.

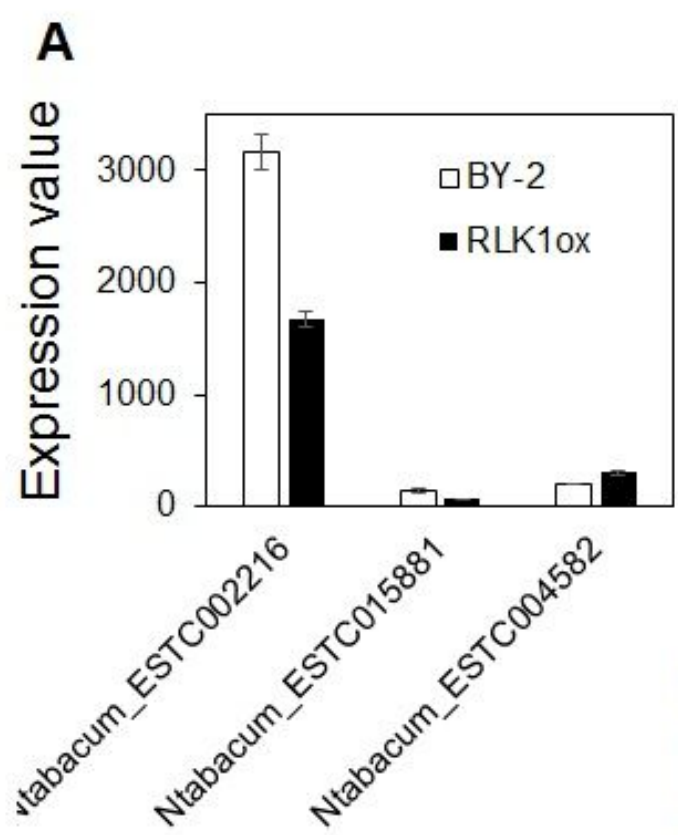

B
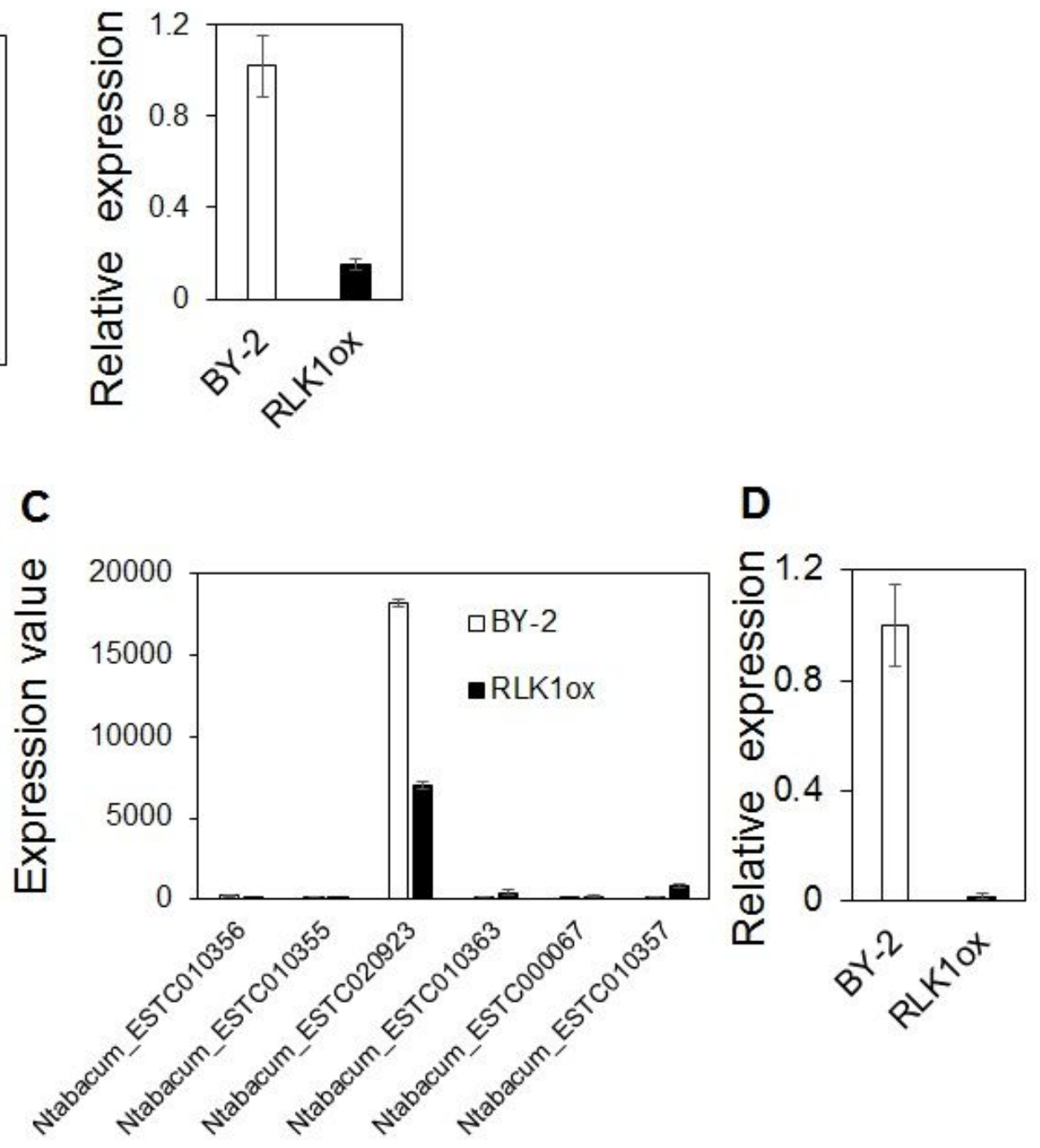

Figure 9

Comparison of expressions of 1-aminocyclopropane-1-carboxylate synthase (ACS) genes and ACO genes between BY-2 cells and RLK1ox cells. (A) The microarray analysis of ACS genes. The expression levels of 2 ACS genes decreased in RLK1 ox cells. (B) Quantitative real-time PCR analysis of expression level of one ACS gene (Ntabacum_ESTC002216). The differences among the two conditions are significant $(P<0.05)$. (C) The microarray analysis of 1-aminocyclopropane-1-carboxylate oxidase (ACO) genes, ethyleneforming enzyme. The expression levels of one ACO gene (Ntabacum_ESTC020923) steeply decreased in RLK1ox cells. (D) Quantitative real-time PCR analysis of expression levels of the ACO gene. Each sample was harvested from 3-days old culture. Error bars represent standard error from the mean $(n=3)$. The 
differences among the two conditions are significant $(P<0.01)$. The relative mRNA levels normalized to that of the ribosomal large subunit L25 gene and the s.e.m.is shown.

\section{Supplementary Files}

This is a list of supplementary files associated with this preprint. Click to download.

- 202006214thTableS2genelist.xlsx

- 202006214thTableS1primers.xls

- 20200624FigS2WEE1RTPCRBYKRLK10x.pptx

- 20200621 suppFig1toFig34thcellsize.pptx 